\title{
Clinical predictors of GH deficiency in surgically cured acromegalic patients
}

\author{
Cheol Ryong $\mathrm{Ku}^{1,2,3}$, Jae Won Hong ${ }^{5}$, Eui Hyun $\mathrm{Kim}^{2,3,4}$, Sun Ho Kim ${ }^{2,3,4}$ and \\ Eun Jig Lee ${ }^{1,2,3}$ \\ ${ }^{1}$ Endocrinology, ${ }^{2}$ Institute of Endocrine Research, ${ }^{3}$ Pituitary Tumor Clinic and ${ }^{4}$ Neurosurgery, Yonsei University \\ College of Medicine, 50 Yonsei-ro, Seodaemun-gu, Seoul 120-752, Republic of Korea and ${ }^{5}$ Department of Internal \\ Medicine, Ilsan-Paik Hospital, College of Medicine, Inje University, Koyang, Gyeonggi-do, Republic of Korea
}

\author{
Correspondence \\ should be addressed \\ to E J Lee or S H Kim \\ Email \\ ejlee423@yuhs.ac or \\ sunkim@yuhs.ac
}

\begin{abstract}
Objective: Even in patients with cured acromegaly, GH deficiency (GHD) after transsphenoidal adenomectomy (TSA) adversely affects body composition and inflammatory biomarkers of cardiovascular risk. In this study, clinical parameters for predicting GHD after TSA in 123 cured acromegalic patients were investigated.

Design and methods: GH levels were measured at $6,12,18,24,48$, and $72 \mathrm{~h}$ after TSA and serial insulin tolerance tests were conducted at 6 months, 2 years, and then every 2 years after TSA.

Results: GHD was found in 12 patients (9.8\%) at 4.1 (range: $0.5-4.1$ ) years after TSA. IGF1 levels were significantly lower at 6 months after TSA in GHD group than intact GH group (175.9 vs 316.8 $\mu \mathrm{g} / \mathrm{l}$, range: 32.0-425.0 and 96.9-547.3 respectively, $P=0.008$ ). Adenomas involving both sides of the pituitary gland were significantly more frequent in GHD patients (29.7 vs $83.3 \% ; P=0.002$ ). Furthermore, immediate postoperative $72-\mathrm{h} \mathrm{GH}$ levels after TSA were significantly lower (0.17 vs 0.45 , range: $0.02-0.93$ and $0.02-5.95$ respectively, $P=0.019$ ) in GHD patients. In multiple logistic regression analysis, bilaterality of tumor involvement (odds ratio $(\mathrm{OR})=10.678, P=0.003 ; 95 \% \mathrm{Cl}=2.248-50.728$ ) and immediate postoperative $72-\mathrm{h} \mathrm{GH}$ level (OR $=0.079, P=0.047 ; 95 \% \mathrm{Cl}=0.006-0.967$ ) showed significant power for predicting GHD.

Conclusions: These data suggest that bilateral involvement of a pituitary adenoma and severely decreased immediate postoperative serum GH levels at $72 \mathrm{~h}$ after TSA may be independent risks factor for accelerated GHD in acromegalic patients.
\end{abstract}

\section{Introduction}

Acromegaly results from excess secretion of growth hormone $(\mathrm{GH})$, mostly caused by a GH-secreting pituitary adenoma (1). Meta-analyses have shown that excess $\mathrm{GH}$ is associated with high mortality caused by cardiovascular disease and metabolic disorders $(2,3)$. The aim of the therapy is to lower the serum insulin-like growth factor 1 (IGF1) concentration to levels within the reference ranges for the patient's age and sex, and to lower serum nadir $\mathrm{GH}$ concentrations during a $75 \mathrm{~g}$ oral glucose tolerance test (OGTT) (4). According to the most recent consensus meetings, biochemical remission after transsphenoidal adenomectomy (TSA) is defined as a nadir GH level $<0.4 \mathrm{ng} / \mathrm{ml}$ on an OGTT (5). In an effort to avoid complications caused by $\mathrm{GH}$ excess in acromegalic patients, serum GH levels for achieving remission are lowered steadily to this target level. However, most therapies neglect the possibility for the development of GH deficiency (GHD) after surgical remission.

Although significant consequences of excess GH secretion do exist, GHD also induces many clinical problems. GHD in adults is associated with a decreased lean body mass and increased fat mass, dyslipidemia, increased frequency of cardiovascular events, lower bone mineral density, and increased mortality $(6,7,8)$. Even in patients with acromegaly, GHD development after treatment adversely affects the body composition and inflammatory biomarkers of cardiovascular risk (9). In cured acromegalic patients with GHD, GH replacement

Published by Bioscientifica Ltd. 
therapy has been proven to improve the body composition, dyslipidemia, and the quality of life without causing any adverse effects such as malignancy or altered glucose metabolism (10). However, no studies have been reported on the development and parameters predictive of GHD in acromegalic patients after surgical remission. In this study, we evaluated the early parameters that might predict GHD after TSA.

\section{Subjects and methods}

\section{Patients}

Among patients at the Severance Hospital Pituitary Tumor Clinic, 158 patients with a GH-secreting pituitary adenoma achieved biochemical remission proved by OGTT after TSA from January 2001 to January 2011 at Yonsei University Health System, Seoul, Korea. The operations were performed by a senior neurosurgeon (S H Kim) $(11,12)$. We evaluated the data for 123 consecutive patients with a GH-secreting pituitary adenoma, who were followed for at least 3 years after TSA until January 2014. Out of 158 patients, 35 were excluded because adequate endocrine evaluations were not conducted after the TSA. The excluded patients had been referred back to the primary hospital of their initial diagnosis after confirmation of cure by both a 1-week and 6-month OGTT after TSA. The clinical manifestations of the 35 excluded patients, including modified Hardy's classifications and preoperative hormonal status, did not differ from those of the 123 included patients (data not shown). Pituitary tumors were classified based on the dynamic magnetic resonance imaging of the sella turcica and parasellar region according to modified Hardy's radiological classifications as described previously (11). Bilaterality of the pituitary adenoma was confirmed by the presence of a tumor beyond the apse midline of the pituitary stalk.

This study was conducted in accordance with the Declaration of Helsinki and approved by our institutional review board.

\section{Biochemical measurements}

Before all operations, serum GH levels were measured with a $75 \mathrm{~g}$ OGTT using a protocol described previously (13). The OGTT was performed 5-6 days after TSA and was followed up at 6-month intervals at least six times, after which the OGTT was conducted annually. An age- and sex-matched normal IGF1 level and a nadir serum GH level $<0.4 \mathrm{ng} / \mathrm{ml}$ in the $75 \mathrm{~g}$ OGTT were considered as representative of biochemical remission (5). Immunoradiometric assay (hGH-RIACT; Cis Bio International, Gif-sur-Yvette, France) was used to measure the GH concentration. The assay had an analytical sensitivity of $0.03 \mu \mathrm{IU} / \mathrm{ml}$; the intra-assay coefficient of variation $(\mathrm{CV})$ was $1.3-2.1 \%$ and the interassay $\mathrm{CV}$ was $3.8-5.0 \%$. The World Health Organization (WHO) international standard (WHO IS 98/574) was used to classify the GH values. An IRMA system (IGF1 NEXT IRMA CT; Biocode-Hycel, Liège, Belgium) was used to measure the IGF1 concentrations. The minimum detectable IGF1 concentration was $1.25 \mathrm{ng} / \mathrm{l}$, the within-assay CV was $2.6-4.4 \%$, and the interassay $C V$ was $7.4-9.1 \%$. Serum GH levels were measured at $6,12,18,24,48$, and $72 \mathrm{~h}$ after TSA.

\section{Function of each pituitary axis}

GHD was diagnosed when the peak GH level was $<3 \mathrm{ng} / \mathrm{ml}$ during an insulin tolerance test (ITT). The concentrations of other pituitary axis hormones were also measured in a combined pituitary function test (CPFT) before and after TSA. CPFTs were conducted serially at 6 months, 2 years, and then every 2 years after TSA. The CPFT was interpreted as described previously $(11,14,15,16)$ and the results were confirmed by two endocrinologists. After i.v. injection of $0.1 \mathrm{U} / \mathrm{kg}$ regular insulin, the responses of serum GH were evaluated serially for $2 \mathrm{~h}$. If nadir serum glucose level was not decreased below $40 \mathrm{mg}$ /day within first $30 \mathrm{~min}$ in ITTs, additional doses of regular insulin were injected to achieve the target nadir glucose level.

\section{Statistical analyses}

Continuous and categorical variables are expressed as medians (range). Data were analyzed using the SPSS Software Package for Windows (version 18.0; IBM Corp., Armonk, NY, USA). The Mann-Whitney $U$ test and the Kruskal-Wallis test were used for continuous variables, and the linear-by-linear association for categorical variables was performed as appropriate. All statistical tests were two tailed, and a $P$ value of $<0.05$ was considered significant.

\section{Results}

\section{Baseline characteristics}

The baseline characteristics of the 123 patients are given in Table 1 . The median age was 44 (21-69) years, and the median follow-up duration was 5.8 (3-12.1) years. The percentages of men and women were 48.8 and $51.2 \%$ 
Table 1 Clinical characteristics according to the development of GH deficiency. The $P$ values were calculated using the MannWhitney $U$ test for continuous variables and the linear-by-linear association for categorical variables, comparing the normal GH axis group with the $\mathrm{GH}$ deficiency group.

\begin{tabular}{|c|c|c|c|c|}
\hline & Total $(n=123)$ & Normal $(n=111)$ & GH deficiency $(n=12)$ & $P$ value \\
\hline Age (years) & $44(21-69)$ & $44(21-69)$ & $52(33-61)$ & 0.047 \\
\hline \multicolumn{5}{|l|}{ Sex } \\
\hline Male & $60(48.8 \%)$ & $57(51.4 \%)$ & $3(25.0 \%)$ & 0.084 \\
\hline Female & $63(51.2 \%)$ & $54(48.6 \%)$ & $9(75.0 \%)$ & \\
\hline Hardy's classification & & & & 0.420 \\
\hline I & $49(39.8 \%)$ & $46(37.4 \%)$ & $3(25.0 \%)$ & \\
\hline II & $28(22.8 \%)$ & $24(21.6 \%)$ & $4(33.3 \%)$ & \\
\hline IIIA & $7(5.7 \%)$ & $6(5.4 \%)$ & $1(8.3 \%)$ & \\
\hline IIIB & $25(20.3 \%)$ & $23(20.7 \%)$ & $2(16.7 \%)$ & \\
\hline IV & $14(11.4 \%)$ & $12(10.8 \%)$ & $2(16.7 \%)$ & \\
\hline Bilaterality of tumor & & & & 0.002 \\
\hline Unilateral & $80(65.0 \%)$ & $78(70.3 \%)$ & $2(16.7 \%)$ & \\
\hline Bilateral & $43(35.0 \%)$ & $33(29.7 \%)$ & $10(83.3 \%)$ & \\
\hline \multicolumn{5}{|c|}{$\mathrm{GH}$ in postoperative period (ng/ml) } \\
\hline $6 \mathrm{~h}$ & $0.53(0.07-3.32)$ & $0.54(0.07-2.82)$ & $0.46(0.10-3.32)$ & 0.878 \\
\hline $12 \mathrm{~h}$ & $0.55(0.08-4.04)$ & $0.55(0.10-4.04)$ & $0.29(0.08-1.36)$ & 0.090 \\
\hline $18 \mathrm{~h}$ & $0.59(0.03-4.55)$ & $0.60(0.14-4.55)$ & $0.31(0.03-1.92)$ & 0.086 \\
\hline $24 \mathrm{~h}$ & $0.50(0.02-4.91)$ & $0.51(0.09-4.91)$ & $0.26(0.03-1.57)$ & 0.210 \\
\hline $48 \mathrm{~h}$ & $0.44(0.01-9.06)$ & $0.46(0.02-9.06)$ & $0.26(0.01-0.83)$ & 0.121 \\
\hline $72 \mathrm{~h}$ & $0.38(0.02-5.95)$ & $0.45(0.02-5.95)$ & $0.17(0.02-0.93)$ & 0.019 \\
\hline \multicolumn{5}{|l|}{ At one week after TSA } \\
\hline Nadir GH in OGTT (ng/ml) & $0.21(0.01-5.26)$ & $0.22(0.01-5.26)$ & $0.14(0.02-0.99)$ & 0.324 \\
\hline IGF1 ( $\mu \mathrm{g} / \mathrm{l})$ & $421.1(108.0-619.1)$ & $425.3(121.2-619.1)$ & 366.6 (108.0-619.1) & 0.262 \\
\hline \multicolumn{5}{|l|}{ At 6 months after TSA } \\
\hline Nadir GH in OGTT (ng/ml) & $0.10(0.01-1.49)$ & $0.10(0.01-1.49)$ & $0.10(0.02-0.38)$ & 0.141 \\
\hline IGF1 ( $\mu \mathrm{g} / \mathrm{I})$ & $314.8(32.0-547.3)$ & $316.8(96.9-547.3)$ & $175.9(32.0-425.0)$ & 0.008 \\
\hline
\end{tabular}

OGTT, oral glucose tolerance test; TSA, transsphenoidal adenomectomy. Statistically significant values are in bold $(P<0.05)$.

respectively. The function of the GH axis and other pituitary hormone axes was evaluated 3 (2-7) times over 4.4 (2-10.5) years. Serum GH levels decreased significantly at $6 \mathrm{~h}$ after TSA and remained $<1.0 \mathrm{ng} / \mathrm{ml}$ in most patients. The mean GH levels were 0.53 (0.07-3.32), 0.55 (0.08$4.04), 0.59$ (0.03-4.55), 0.50 (0.02-4.91), 0.44 (0.01-9.06), and $0.38(0.02-5.95) \mathrm{ng} / \mathrm{ml}$ at $6,12,18,24,48$, and $72 \mathrm{~h}$ after TSA respectively. One week after TSA, the median nadir GH level during OGTT was $0.21(0.01-5.26) \mathrm{ng} / \mathrm{ml}$ and the median IGF1 level was $421.1(108.0-619.1) \mu \mathrm{g} / \mathrm{l}$.

\section{GHD after TSA}

A total of 123 patients were enrolled in this study. As these patients were acromegalic, all of them had nadir GH levels above $3 \mathrm{ng} / \mathrm{ml}$ in ITTs and exhibited increased IGF1 levels above their age- and sex-matched normal ranges before TSA. Out of the 123 patients, 12 (9.8\%) developed GHD after TSA (Table 1). Patients with GHD were older (52 vs 44 years, range: $33-61$ and 21-69 respectively, $P=0.047$ ) than those with intact GH-secretory function. The two groups did not differ in sex, preoperative GH and IGF1 levels, follow-up duration, and Hardy's classifications, which reflect the size and the invasiveness of the tumors. Concerning the bilaterality of tumor involvement, adenomas involving both sides of the pituitary gland were significantly more frequently noted in GHD patients (29.7 vs $83.3 \% ; P=0.002$ ). In immediate postoperative analysis during the $72 \mathrm{~h}$ after TSA, GH levels at 6, 12, 18, 24, and $48 \mathrm{~h}$ were not significantly lower in the GHD group than in the group with intact GH function. Only GH levels at $72 \mathrm{~h}$ after TSA differed significantly between the two groups (0.17 vs $0.45 \mathrm{ng} / \mathrm{ml}$, range: $0.02-0.93$ and $0.02-$ 5.95 respectively, $P=0.019$ ). At 6 months after TSA, nadir GH levels during OGTT did not differ between the group with intact GH function and the GHD group (0.10 vs $0.10 \mathrm{ng} / \mathrm{ml}$, range: $0.02-0.38$ and $0.01-1.49$ respectively, $P=0.141)$. However, IGF1 level was significantly lower at 6 months after TSA in the GHD group (175.9 vs $316.8 \mu \mathrm{g} / \mathrm{l}$, range: $32.0-425.0$ and $96.9-547.3$ respectively, $P=0.008$ ).

Out of the 111 patients with intact GH-secretory function, five experienced transient GHD after TSA. Two (both men) of the patients were diagnosed with GHD at the initial ITTs performed at 6 months after TSA. However, they had maintained a normal response of the GH axis in subsequent ITTs since 2 and 4 years after TSA respectively. 
In the other three patients (one woman and two men), transient GHD was found at 4 years after TSA, which recovered thereafter.

Out of the 12 patients with GHD, four (three women and one man) presented with persistent deficiency of the $\mathrm{GH}$ axis since the initial ITTs were performed at 6 months after TSA. The age of these patients was 55 (50-60) years. Out of the 12 patients with GHD, eight had intact function of the GH axis in the initial ITTs. However, GHD had developed since 3.7 (2.1-4.1) years after TSA. The mean age of these patients was 51.5 (31-61) years, and six of these eight patients were women (Table 2).

\section{Seventy-two hours GH after TSA}

Patients were categorized into four quartiles according to the GH levels at $72 \mathrm{~h}$ after TSA (Table 3 ). The incidence of GHD increased and the female:male ratio decreased linearly with decreasing quartile $(P=0.044$ and 0.003 respectively). Furthermore, all the immediate postoperative GH levels including those at $6,12,18,24,48$, and $72 \mathrm{~h}$ after TSA decreased significantly with decreasing quartile (all $P<0.001$ ). However, age, preoperative GH and IGF1 concentrations, Hardy's classifications, and bilaterality of the pituitary adenoma did not differ between each of the quartile groups. Multiple logistic regression analysis revealed that the odds ratio (OR) for GHD increased significantly across decreasing postoperative $\mathrm{GH}$ levels at $72 \mathrm{~h}(\mathrm{OR}=0.079, P=0.047,95 \% \mathrm{CI}=0.006-0.967)$ (Table 4). When the $72 \mathrm{~h} \mathrm{GH}$ level increased to $1 \mathrm{ng} / \mathrm{ml}$, the risk rate for the development of GHD decreased to 0.086. In receiver-operative characteristic (ROC) analysis,

Table 2 Clinical characteristics of cured acromegalic patients with $\mathrm{GH}$ deficiency.

\begin{tabular}{|c|c|c|c|c|c|}
\hline No. & $\begin{array}{c}\text { Age } \\
\text { (years) }\end{array}$ & Sex & $\begin{array}{c}\text { Hardy } \\
\text { type }\end{array}$ & $\begin{array}{l}\text { Tumor } \\
\text { location }\end{array}$ & $\begin{array}{c}\text { Onset of GH } \\
\text { deficiency after } \\
\text { TSA (years) }\end{array}$ \\
\hline 1 & 56 & $\mathrm{~F}$ & I & Bilateral & 0.5 \\
\hline 2 & 54 & $\mathrm{~F}$ & II & Bilateral & 0.5 \\
\hline 3 & 60 & $\mathrm{~F}$ & IIIA & Bilateral & 0.5 \\
\hline 4 & 50 & $\mathrm{M}$ & IIIB & Bilateral & 0.5 \\
\hline 5 & 51 & $F$ & I & Bilateral & 2.1 \\
\hline 6 & 61 & $\mathrm{~F}$ & I & Left & 4.0 \\
\hline 7 & 52 & $F$ & II & $\begin{array}{l}\text { Left with } \\
\text { empty sellar }\end{array}$ & 3.7 \\
\hline 8 & 53 & $F$ & II & Bilateral & 2.0 \\
\hline 9 & 52 & $\mathrm{~F}$ & IIIB & Left & 4.1 \\
\hline 10 & 31 & $\mathrm{~F}$ & IV & Bilateral & 3.8 \\
\hline 11 & 33 & $\mathrm{M}$ & II & Bilateral & 3.7 \\
\hline 12 & 41 & $\mathrm{M}$ & IV & Bilateral & 2.0 \\
\hline
\end{tabular}

the $\mathrm{GH}$ level at $72 \mathrm{~h}$ after TSA was a reliable factor for predicting the GHD with a value of the area under the ROC curve of 0.706 . The predictive value was maximal when the cutoff value was $0.23 \mathrm{ng} / \mathrm{ml}$. For $72 \mathrm{~h} \mathrm{GH}$ levels below $0.23 \mathrm{ng} / \mathrm{ml}$, we recorded a sensitivity of $58.3 \%$ and a specificity of $79.3 \%$ for predicting the presence of GHD (Table 5).

\section{Extent of tumor involvement}

The bilaterality of the pituitary adenoma before TSA was defined according to the existence of a tumor beyond the apse midline of the pituitary stalk. Although there was no difference in age, sex, and immediate postoperative $\mathrm{GH}$ level, GHD developed more frequently in patients with pituitary adenoma involving a bilateral pituitary gland compared with those with a tumor in a unilateral site (23.3 vs $23.3 \% ; P=0.002$; Table 1 ). In multiple regression analysis, bilateral involvement of a pituitary adenoma increased the risk of GHD significantly $(\mathrm{OR}=10.678$, $P=0.003,95 \% \mathrm{CI}=2.248-50.728$; Table 4 ).

\section{Changes in other pituitary hormones accompanied by GHD}

The functions of other pituitary axes, including gonadotropins, thyroid-stimulating hormone (TSH), adrenocorticotropic hormone (ACTH), and prolactin, were evaluated together with the GH axis (Fig. 1) in the 123 cured patients. Patients who developed postoperative GHD had greater incidences of preoperative deficiencies in the TSH axis (58.3 vs $23.4 \%$ ) and ACTH axis (66.7 vs $31.5 \%$ ) before TSA, compared with subjects with a postoperative intact GH axis. In patients with GHD that developed after TSA, preoperative hypopituitarism in all pituitary axes was more frequent (75.0 vs $50.5 \%$ ).

At 6 months after TSA, the normal pituitary function was maintained in 43 patients (35.0\%) and improvement of preoperative hypopituitarism was noted in 46 patients (37.4\%). Hypopituitarism persisted in 27 patients $(22.0 \%)$ and anterior pituitary function worsened in seven patients $(5.7 \%)$. Out of the 12 patients with GHD, two (16.7\%) had isolated GHD. GHD was significantly associated with persistent and worsening function of each axis, including gonadotropins, TSH, ACTH, and prolactin.

\section{Discussion}

In this study, we have evaluated the early clinical parameters for GHD in remitted acromegalic patients 
Table 3 Baseline characteristics according to postoperative 72-h GH quartile categories. The Kruskal-Wallis test was used for continuous variables and the linear-by-linear association for categorical variables.

\begin{tabular}{|c|c|c|c|c|c|}
\hline \multirow[b]{2}{*}{ Variables } & \multicolumn{5}{|c|}{ Quartile of postoperative 72-h GH } \\
\hline & $\mathrm{Q} 1(n=34)$ & $\mathrm{Q} 2(n=28)$ & $\mathrm{Q} 3(n=31)$ & $\mathrm{Q} 4(n=30)$ & $P$ value \\
\hline $\begin{array}{l}\text { Range of } 72-\mathrm{h} \text { GH after } \\
\text { TSA (ng/ml) }\end{array}$ & $0.02-0.24$ & $0.25-0.38$ & $0.39-0.89$ & $0.90-5.95$ & \\
\hline Incidence of GH deficiency & $7(20.6 \%)$ & $1(3.6 \%)$ & $3(9.7 \%)$ & $1(3.3 \%)$ & 0.044 \\
\hline Age (years) & $43(22-60)$ & $45(28-62)$ & $45(24-66)$ & $49(21-69)$ & 0.088 \\
\hline Sex & & & & & 0.003 \\
\hline Male & $21(61.8 \%)$ & $17(60.7 \%)$ & $14(45.2 \%)$ & $8(26.7 \%)$ & \\
\hline Female & $13(38.2 \%)$ & $11(39.3 \%)$ & $17(54.8 \%)$ & $22(73.3 \%)$ & \\
\hline Preoperative GH (ng/ml) & $16.71(1.31-68.00)$ & $16.80(1.31-47.35)$ & $10.70(1.42-56.33)$ & $13.23(2.30-92.00)$ & 0.372 \\
\hline Preoperative IGF1 ( $\mu \mathrm{g} / \mathrm{l})$ & $600.0(514.0-1098.9)$ & 612.5 (550.0-1098.9) & $598.4(480-949.5)$ & $632.5(336.0-1085.3)$ & 0.727 \\
\hline $\begin{array}{l}\text { Follow-up duration } \\
\text { (years) }\end{array}$ & $5.1(3-10.7)$ & $4.4(3-10.5)$ & $5.9(3-10.9)$ & $4.4(3-9.7)$ & 0.443 \\
\hline $\begin{array}{l}\text { No. of insulin tolerance } \\
\text { tests }\end{array}$ & $2(2-5)$ & $2(2-4)$ & $3(2-5)$ & $2(2-4)$ & 0.689 \\
\hline $\begin{array}{l}\text { Follow-up of insulin tol- } \\
\text { erance test (years) }\end{array}$ & $4.7(2-10.0)$ & $4.7(2-8.9)$ & $4.8(2-8.5)$ & $3.9(2-8.3)$ & 0.726 \\
\hline Hardy's classification & & & & & 0.102 \\
\hline I & $11(32.4 \%)$ & $11(39.3 \%)$ & $10(32.3 \%)$ & $17(56.7 \%)$ & \\
\hline II & $8(23.5 \%)$ & $5(17.9 \%)$ & $9(29.0 \%)$ & $6(20 \%)$ & \\
\hline IIIA & $2(5.9 \%)$ & $2(7.1 \%)$ & $2(6.5 \%)$ & $1(3.3 \%)$ & \\
\hline IIIB & $10(29.4 \%)$ & $5(17.9 \%)$ & $7(22.6 \%)$ & $3(10 \%)$ & \\
\hline IV & $3(8.8 \%)$ & $5(17.9 \%)$ & $3(9.7 \%)$ & $3(10 \%)$ & \\
\hline Bilaterality of tumor & & & & & 0.213 \\
\hline Unilateral & $20(58.8 \%)$ & $19(67.9 \%)$ & $19(61.3 \%)$ & $23(76.7 \%)$ & \\
\hline Bilateral & $14(41.2 \%)$ & $9(22.1 \%)$ & $12(38.7 \%)$ & $7(23.3 \%)$ & \\
\hline $\begin{array}{l}\text { Nadir GH in OGTT at a } \\
\text { week after TSA }(\mathrm{ng} / \mathrm{ml})\end{array}$ & $0.09(0.01-0.77)$ & $0.23(0.02-0.69)$ & $0.27(0.02-2.34)$ & $0.44(0.07-5.26)$ & $<0.001$ \\
\hline $\begin{array}{l}\text { IGF1 at a week after TSA } \\
(\mu \mathrm{g} / \mathrm{l})\end{array}$ & $464.1(108.0-614.0)$ & $405.4(167.4-619.1)$ & $424.6(121.2-600.0)$ & 367.6 (217.9-590.8) & 0.277 \\
\hline
\end{tabular}

OGTT, oral glucose tolerance test; TSA, transsphenoidal adenomectomy. Statistically significant values are in bold $(P<0.05)$.

after TSA. This study demonstrated the following findings: i) low $72 \mathrm{~h}$ random $\mathrm{GH}$ level (below $0.23 \mathrm{ng} / \mathrm{ml}$ ) after TSA and bilateral involvement of the GH-secreting pituitary adenoma, not the tumor size or invasiveness, have increased the risk of GHD; ii) deficiencies of other pituitary hormone axes are more frequent in cured acromegalic patients both before and after TSA; and iii) some patients experience transient or delayed onset of GHD after TSA.

GHD exerts adverse effects on body composition, cardiovascular disease, lipid profile, psychological function, bone mineral density, and mortality (6). The availability of GH preparations now prevents these adverse effects even in acromegalic patients (9). However, there have been scarce reports on the biochemical markers for GHD in cured acromegalic patients.

Only two reports have evaluated GHD after TSA in patients with acromegaly $(17,18)$. Their studies used GHRH plus arginine stimulation tests to confirm the diagnosis of GHD in a cross-sectional study design. In this study, the GH axis was evaluated using serial ITTs after
TSA in cured patients, and 12 out of 123 patients (9.8\%) developed GHD. The GH axis was evaluated serially at least twice with a relatively long follow-up duration (4.4, range: $2-10.5$ years). With regard to the methods carried out to stimulate the GH axis, several studies were conducted and they did not find any differences between the GHRH plus arginine test and the ITT for detecting GHD in cured acromegalic patients $(19,20)$. Although the peak GH levels were lower in the ITT than in the GHRH plus arginine test, the accuracy for diagnosis of GHD is equivalent (20).

Ronchi et al. (18) suggested that a larger tumor, higher preoperative GH level, and the existence of other pituitary deficiencies might be candidate markers for predicting GHD after TSA in cured patients. Yamada et al. (17) also suggested that GHD patients had twice as high mean values of GH levels and tumor volumes as GH-sufficient patients, although there were no statistical differences. Both suggested that aggressive surgical removal of GH-secreting pituitary adenomas could lead to GHD combined with deficiency of other pituitary axes. In this study, there were 
Table 4 Multiple logistic regression for GH deficiency.

\begin{tabular}{|c|c|c|c|}
\hline & Odds ratio & $95 \% \mathrm{Cl}$ & $P$ value \\
\hline Age (years) & 1.075 & $0.997-1.160$ & 0.059 \\
\hline $\operatorname{Sex}(F)$ & 3.514 & $0.664-18.597$ & 0.139 \\
\hline $\begin{array}{l}\text { Bilaterality of } \\
\text { tumor (bilateral) }\end{array}$ & 10.678 & $2.248-50.728$ & 0.003 \\
\hline $\begin{array}{l}\text { 72-h GH after TSA } \\
\text { (ng/ml) }\end{array}$ & 0.079 & $0.006-0.967$ & 0.047 \\
\hline
\end{tabular}

TSA, transsphenoidal adenomectomy. Bold characters represent the statistically significance $(P<0.05)$

no differences in sex, preoperative GH and IGF1 levels, tumor size, or tumor invasiveness between the GHD patients and patients with intact GH function, except for older age observed in patients with GHD. The differences in prognostic factors for GHD might be caused by the characteristics of the enrolled patients and the extent of surgical resection of the GH-secreting pituitary adenomas. The age of the patients was 44 (range: 21-69) years in this study, which is about 10 years younger than those patients in previous studies $(17,18)$. Younger age means that enrolled patients had shorter periods of acromegaly than those patients in previous studies. Considering that the mean age at the initial diagnosis of acromegaly was in the mid-1940s in this study, the older age of the cohorts used in previous studies might have biased the results (21). Longer duration of exposure to high IGF1 levels could suppress normal somatotropes, leading to the occurrence of GHD, as in previous studies. Regarding the extent of surgical resection, some studies have reported that aggressive surgical resection of a GH-secreting pituitary adenoma can cause hypopituitarism, including GHD (22). However, in our previous study, we reported that extensive adenoidectomy achieved higher biochemical remission rates with no differences in the rate of complete resection (11). In that report, an aggressive approach did not aggravate but rather improved postoperative hypopituitarism. Even in the GH axis, there was no difference in the incidence of development of GHD, compared with other studies $(23,24)$. Specifically, the incidence of GHD was $9.8 \%$ in this study, compared with 6.1 and $9.1 \%$ in other studies $(17,18)$.

Considering the role of the pituitary gland as a center of the hormone system, acromegalic patients with GH-secreting pituitary adenoma might exhibit different changes in the GH axis after achieving biochemical remission via TSA. One possible background for this phenomenon is a feedback system within multiple hormonal axes. As the pituitary gland is the main organ orchestrating the feedback system of multiple endocrine hormones, hyperfunctioning pituitary adenoma might influence the physiology of normal cells in the pituitary gland. For example, the secretory function of a normal corticotrope, which secrets $\mathrm{ACTH}$, is suppressed in Cushing's disease. The immediate postoperative serum cortisol concentration has a significant value both for predicting long-term remission and for recovery from hypocortisolemia in Cushing's disease after TSA $(25,26)$. Similarly, GHD after TSA in a cured acromegalic patient might be caused by negative feedback, originating from the preoperative oversecretion of GH. In this study, patients with transient GHD after TSA had a higher IGF1 level than those with consistently intact secretory function of GH after TSA (898 vs 720, range: $750-1053$ and $336.0-1098.9 \mu \mathrm{g} / 1$ respectively), although there was no statistical significance. The other reason for an altered GH axis after TSA could be the location of normal somatotropes. Generally, normal somatotropes are found in the lateral portions of the pituitary gland (27). As demonstrated in Tables 1 and 2, adenomas involving both sides of the pituitary gland showed an increased risk of GHD. These results could be explained by two possible causes, which are surgical complication and remnant amount of normal somatotropes in pituitary gland. Considering that there was no difference in recovery of other pituitary hormone axes according to the bilaterality of pituitary adenomas, this could be explained by remnant secretory

Table 5 Probability of GH deficiency according to the GH level at $72 \mathrm{~h}$ after TSA.

\begin{tabular}{|c|c|c|c|}
\hline $\begin{array}{l}\text { 72-h GH after } \\
\text { TSA (ng/ml) }\end{array}$ & Sensitivity (\%) & Specificity (\%) & AUC \\
\hline 0.02 & 8.3 & 99.1 & 53.715 \\
\hline 0.03 & 16.7 & 99.1 & 57.885 \\
\hline 0.04 & 25.0 & 98.2 & 61.600 \\
\hline 0.05 & 33.3 & 97.3 & 65.315 \\
\hline 0.12 & 33.3 & 91.0 & 62.160 \\
\hline 0.15 & 41.7 & 90.1 & 65.880 \\
\hline 0.16 & 41.7 & 88.3 & 64.980 \\
\hline 0.17 & 50.0 & 87.4 & 68.695 \\
\hline 0.22 & 50.0 & 79.3 & 64.640 \\
\hline 0.23 & 58.3 & 79.3 & 68.805 \\
\hline 0.37 & 58.3 & 52.3 & 55.290 \\
\hline 0.38 & 66.7 & 51.4 & 59.010 \\
\hline 0.54 & 66.7 & 44.1 & 55.405 \\
\hline 0.59 & 75.0 & 44.1 & 59.570 \\
\hline 0.6 & 75.0 & 43.2 & 59.120 \\
\hline 0.62 & 83.3 & 43.2 & 63.285 \\
\hline 0.81 & 83.3 & 31.5 & 57.430 \\
\hline 0.84 & 91.7 & 29.7 & 60.700 \\
\hline 0.9 & 91.7 & 25.2 & 58.450 \\
\hline 0.93 & 100 & 24.3 & 62.160 \\
\hline 5.95 & 100 & 0 & 50.000 \\
\hline
\end{tabular}

AUC, area under the curve; TSA, transsphenoidal adenomectomy. 


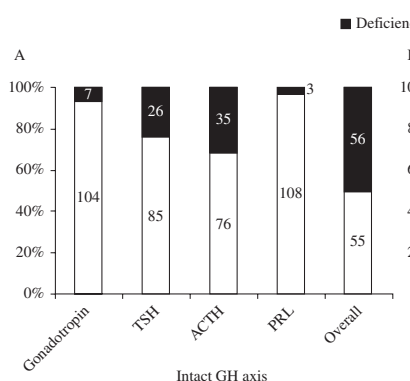

- Deficiency $\square$ Norma
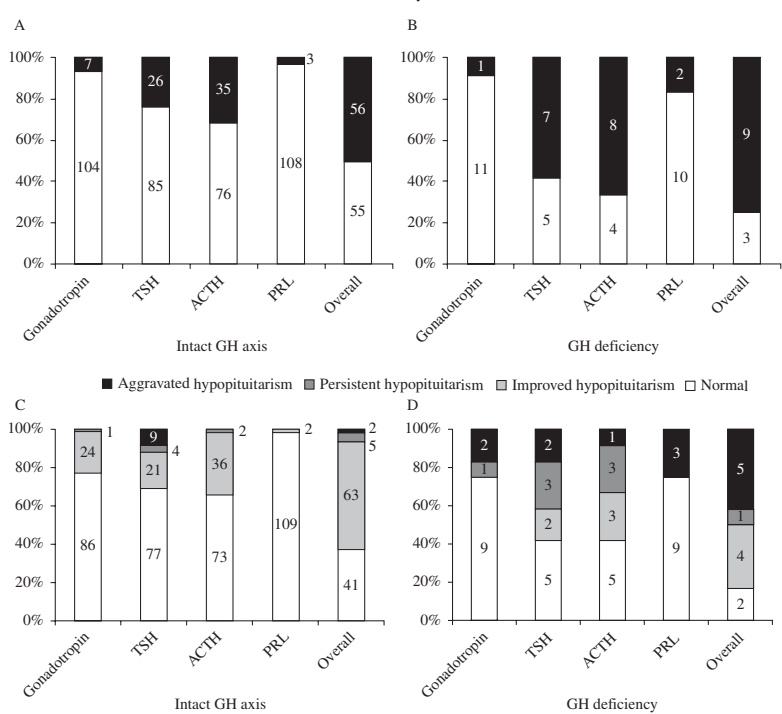

Figure 1

Changes in hormones of each pituitary axis before and after transsphenoidal adenomectomy. The secretory function of each pituitary hormone was compared before ( $A$ and $B$ ) and after ( $C$ and $D$ ) surgery between the group with an intact $\mathrm{GH}$ axis ( $A$ and $C$ ) and the $\mathrm{GH}$-deficient group ( $\mathrm{B}$ and $\mathrm{D}$ ). After surgery, $P$ values were 0.033 for gonadotropin, 0.040 for TSH, 0.001 for $\mathrm{ACTH},<0.001$ for prolactin (PRL), and $<0.001$ for the overall pituitary hormone axis (linear-by-linear association).

reservoirs of normal somatotropes rather than a surgical complication. It is unclear as to how the GH-secreting pituitary adenoma influences the remnant secretory reservoirs of a normal somatotrope. However, a previous study demonstrated an autocrine/paracrine effect of GH on individual tissues (28), suggesting that GH itself from pituitary adenomas involving both sides of the pituitary gland could influence normal somatotropes.

If biochemical cure is achieved after TSA in patients with acromegaly, serum GH concentration decreases to normal within $1-2 \mathrm{~h}$ and serum IGF1 level normalizes within 7-10 days to several months (29). Early postoperative changes in GH after TSA in a cured acromegalic patient provide meaningful information for postoperative management. For example, we previously suggested that the immediate postoperative GH level could be a useful predictor of long-term outcomes in acromegalic patients (12). In our previous study, we identified that the GH level at $24 \mathrm{~h}$ after TSA could be an early predictor for biochemical remission of acromegalic patients (12). Nonetheless, in this study, although the serum GH concentration $24 \mathrm{~h}$ after TSA showed the highest predictive value for long-term control of acromegaly, the serum GH concentration $72 \mathrm{~h}$ after TSA was the strongest predictor of GHD. In ROC analysis, the GH level at $72 \mathrm{~h}$ after TSA was a reliable factor for predicting GHD. The predictive value was maximal when the cutoff value was $0.23 \mathrm{ng} / \mathrm{ml}$ with a sensitivity of $58.3 \%$ and a specificity of $79.3 \%$ (Table 5). While a tumor is secreting excessive GH, the normal somatotrope cells are under negative feedback from increased GH/IGF1 levels in acromegalic patients. Furthermore, the half-time of endogenous GH disappearance is $\sim 20 \mathrm{~min}$ (30). These are the reasons that the immediate postoperative GH level at $24 \mathrm{~h}$ after TSA could uncover meaningful information in long-term remission. Concerning the occurrence of GHD and the recovery of suppressed normal somatotropes, it is unclear as to when the suppressed normal somatotrope cells recover their secretory function. However, these results suggest that the $\mathrm{GH}$ level at $72 \mathrm{~h}$ might reflect the presence of reservoirs of $\mathrm{GH}$ for secretory function in normal somatotropes after the loss of GH originating from a pituitary adenoma.

The ITT-induced stimulation test of the GH axis was conducted serially at 6 months, 2 years, and then every 2 years after TSA in this study. Most patients (89.4\%) had a sustained change in the GH axis after TSA after the initial ITT. However, 13 patients (10.6\%) experienced altered status in the GH axis, including five patients (4.1\%) with transient GHD during the follow-up and eight patients (6.5\%) with delayed development of GHD. Among the five patients with transient GHD, two presented with transient GHD at the initial ITT performed at 6 months after TSA. Although mostly surgery-induced transient hypopituitarism develops within 3-4 months after TSA, these two patients might have experienced GHD, which was caused by TSA. The other three patients showed intact GH axis in the initial ITT followed by transient GHD with in 4 years after TSA. Considering that they had age- and sex-matched normal IGF1 at that time, a false-positive result of the ITT at that time could involve the interpretation as transient changes of GH axis. In eight patients with delayed GHD, it was found that all of them presented with GHD in at least one additional ITT after an initial positive test for GHD, which produced the same results thereafter (two additional ITTs in one patient and one additional ITT in the other seven subjects). There was no difference in the duration or the number of ITTs during the follow-up, preoperative serum GH and IGF1 levels, or Hardy's classification. However, most of the transient GHD groups comprised men (4/5), and most of the delayed GHD groups comprised women (6/8). Most female patients (5/6) who developed delayed GHD received TSA at the 6th 
decade of age, which is the perimenopause age. This suggests that estradiol $\left(\mathrm{E}_{2}\right)$ level could be a cause for the development of delayed GHD. As reported previously, menopause could influence the development of GHD in perimenopause female patients (31). In this study, all the female patients with delayed GHD had a decreased $\mathrm{E}_{2}$ level below $20 \mathrm{pg} / \mathrm{dl}$ at the time of GHD onset.

There were four patients who presented with the persistent GHD after TSA. They showed persistent GHD in ITTs, which were conducted twice in three patients and three times in one patient. Although the peak GH level in postoperative serial ITTs remained consistently below $1 \mathrm{ng} / \mathrm{ml}$ in three patients and below $1.5 \mathrm{ng} / \mathrm{ml}$ in one patient, there might exist the chance of changing $\mathrm{GH}$ axis thereafter. However, the probabilities for changes of $\mathrm{GH}$ axis in these four patients should be low because the relatively long follow-up durations for ITTs were applied.

At the time point of stabilization of $\mathrm{GH}$ axis, most patients who experienced alteration in the $\mathrm{GH}$ axis maintained consistent secretory function of the $\mathrm{GH}$ axis at 4 years after TSA. These results suggest that cured acromegalic patients should be followed, assessing the $\mathrm{GH}$ axis, and that $\mathrm{GH}$ replacement treatment should be considered for at least 4 years after TSA. Most patients who had alterations in the GH axis experienced changes in the GH-secretory function at 4 years after TSA.

There were significant differences in preoperative and postoperative secretory functions of other pituitary axes with the development of GHD after TSA. Patients with GHD after TSA had more frequent hypopituitarism before and after TSA. The increased incidence of preoperative and postoperative hypopituitarism suggests that oversecretion of GH together with tumor volume could also influence the secretory functions of pituitary axes other than $\mathrm{GH}$ secretion from normal somatotropes. It is not clear as to why preoperative deficiencies of TSH and ACTH were more frequent in postoperative GHD patients.

In conclusion, these data provide the first clinical evidence that bilateral involvement of a pituitary adenoma and severely decreased immediate postoperative serum GH levels at $72 \mathrm{~h}$ after TSA may be independent risk factors for accelerated GHD in acromegalic patients. Although there is controversy over the validity of $\mathrm{GH}$ replacement therapy for cured GHD patients with acromegaly, these data present clinical information for evaluating patients with acromegaly for $\mathrm{GH}$ axis aberrations. A larger study population with long-term follow-up is required to confirm the clinical validity of these predicting biochemical markers for GHD in cured acromegalic patients.
Declaration of interest

The authors declare that there is no conflict of interest that could be perceived as prejudicing the impartiality of the research reported.

\section{Funding}

This work was supported by the National Research Foundation of Korea (NRF) grant funded by the Korean Government (MEST) (No. 2011-0016060).

\section{Author contribution statement}

C R Ku was involved in the conceptualization of the manuscript, collection of data, data analysis, and writing of the manuscript. J W Hong performed data collection and analysis, and wrote the manuscript. E H Kim collected and analyzed the data, and reviewed the manuscript. S H Kim and E J Lee were involved in the conceptualization of the manuscript, collection of data, and review of the manuscript, and were guarantors of the manuscript.

\section{Acknowledgements}

The authors would like to appreciate Juyoon Park, RN, MPH, OCN; Hae Won Kim, RN; Ji Hye Han, RN; Min Kyeong Jang, RN; Sung Ja Kang, RN; and Bok Soon Lee, RN, Pituitary Tumor Clinic; and Soo Yeon Choi, MPH, Department of Medical Recording, for their tremendous effort in performing the pituitary function tests and data acquisition for such a long follow-up duration.

\section{References}

1 Melmed S. Medical progress: acromegaly. New England Journal of Medicine 2006355 2558-2573. (doi:10.1056/NEJMra062453)

2 Dekkers OM, Biermasz NR, Pereira AM, Romijn JA \& Vandenbroucke JP. Mortality in acromegaly: a metaanalysis. Journal of Clinical Endocrinology and Metabolism 200893 61-67. (doi:10.1210/jc.2007-1191)

3 Maison P, Tropeano A, Macquin Mavier I, Giustina A \& Chanson P. Impact of somatostatin analogs on the heart in acromegaly: a metaanalysis. Journal of Clinical Endocrinology and Metabolism 200792 1743-1747. (doi:10.1210/jc.2006-2547)

4 Freda PU, Post KD, Powell JS \& Wardlaw SL. Evaluation of disease status with sensitive measures of growth hormone secretion in 60 postoperative patients with acromegaly. Journal of Clinical Endocrinology and Metabolism 199883 3808-3816. (doi:10.1210/jcem.83.11.5266)

5 Giustina A, Chanson P, Bronstein MD, Klibanski A, Lamberts S, Casanueva FF, Trainer P, Ghigo E, Ho K \& Melmed S. A consensus on criteria for cure of acromegaly. Journal of Clinical Endocrinology and Metabolism 201095 3141-3148. (doi:10.1210/jc.2009-2670)

6 Carroll PV, Christ ER, Bengtsson BA, Carlsson L, Christiansen JS, Clemmons D, Hintz R, Ho K, Laron Z, Sizonenko P et al. Growth hormone deficiency in adulthood and the effects of growth hormone replacement: a review. Growth Hormone Research Society Scientific Committee. Journal of Clinical Endocrinology and Metabolism $1998 \mathbf{8 3}$ 382-395. (doi:10.1210/jcem.83.2.4594)

7 Hoffman AR, Kuntze JE, Baptista J, Baum HB, Baumann GP, Biller BM Clark RV, Cook D, Inzucchi SE, Kleinberg D et al. Growth hormone (GH) replacement therapy in adult-onset GH deficiency: effects on body composition in men and women in a double-blind, randomized, placebo-controlled trial. Journal of Clinical Endocrinology and Metabolism 200489 2048-2056. (doi:10.1210/jc.2003-030346) 
8 Svensson J, Bengtsson BA, Rosén T, Odén A \& Johannsson G. Malignant disease and cardiovascular morbidity in hypopituitary adults with or without growth hormone replacement therapy. Journal of Clinical Endocrinology and Metabolism 200489 3306-3312. (doi:10.1210/ jc.2003-031601)

9 Lin E, Wexler TL, Nachtigall L, Tritos N, Swearingen B, Hemphill L, Loeffler J, Biller BM, Klibanski A \& Miller KK. Effects of growth hormone deficiency on body composition and biomarkers of cardiovascular risk after definitive therapy for acromegaly. Clinical Endocrinology 201277 430-438. (doi:10.1111/j.1365-2265.2012.04361.x)

10 Giavoli C, Profka E, Verrua E, Ronchi CL, Ferrante E, Bergamaschi S, Sala E, Malchiodi E, Lania AG, Arosio M et al. GH replacement improves quality of life and metabolic parameters in cured acromegalic patients with growth hormone deficiency. Journal of Clinical Endocrinology and Metabolism 201297 3983-3988. (doi:10.1210/ jc.2012-2477)

$11 \mathrm{Ku}$ CR, Kim EH, Oh MC, Lee EJ \& Kim SH. Surgical and endocrinological outcomes in the treatment of growth hormone-secreting pituitary adenomas according to the shift of surgical paradigm. Neurosurgery 201271 ons192-ons203. (doi:10.1227/NEU.0b013e318265a288)

12 Kim EH, Oh MC, Lee EJ \& Kim SH. Predicting long-term remission by measuring immediate postoperative growth hormone levels and oral glucose tolerance test in acromegaly. Neurosurgery 201270 1106-1113. (doi:10.1227/NEU.0b013e31823f5c16)

13 Kreutzer J, Vance ML, Lopes MB \& Laws ER. Surgical management of GH-secreting pituitary adenomas: an outcome study using modern remission criteria. Journal of Clinical Endocrinology and Metabolism 2001 86 4072-4077. (doi:10.1210/jcem.86.9.7819)

14 Melmed S \& Kleinberg D. Anterior pituitary. In Williams Textbook of Endocrinology, 11th edn, pp 240-242. Eds H Kronenberg \& RH Williams. Philadelphia, PA, USA: Elsevier Saunders, 2008.

15 Melmed S \& Jameson JL. Disorders of the anterior pituitary and hypothalamus. In Harrison's Principles of Internal Medicine, 17th edn, pp 2195-2216. Eds AS Fauci, E Braunwald, DL Kasper, SL Hauser, DL Longo, JL Jameson \& J Loscalzo. New York: McGraw-Hill Medical, 2008.

16 Lee EJ, Ahn JY, Noh T, Kim SH \& Kim TS. Tumor tissue identification in the pseudocapsule of pituitary adenoma: should the pseudocapsule be removed for total resection of pituitary adenoma? Neurosurgery 200964 62-69, (discussion 69). (doi:10.1227/01.NEU. $0000330406.73157 .49)$

17 Yamada S, Fukuhara N, Nishioka H, Takeshita A, Suzuki H, Miyakawa M $\&$ Takeuchi Y. GH deficiency in patients after cure of acromegaly by surgery alone. European Journal of Endocrinology 2011165 873-879. (doi:10.1530/EJE-11-0657)

18 Ronchi CL, Giavoli C, Ferrante E, Verrua E, Bergamaschi S, Ferrari DI, Corbetta S, Montefusco L, Arosio M, Ambrosi B et al. Prevalence of GH deficiency in cured acromegalic patients: impact of different previous treatments. European Journal of Endocrinology 2009 161 37-42. (doi:10.1530/EJE-09-0222)

19 Conceição FL, Fisker S, Andersen M, Kaal A, Jørgensen JO, Vaisman M \& Christiansen JS. Evaluation of growth hormone stimulation tests in cured acromegalic patients. Growth Hormone \& IGF Research 200313 347-352. (doi:10.1016/S1096-6374(03)00124-2)

20 van der Klaauw AA, Pereira AM, van Thiel SW, Smit JW, Corssmit EP, Biermasz NR, Frolich M, Iranmanesh A, Veldhuis JD, Roelfsema F et al. GH deficiency in patients irradiated for acromegaly: significance of GH stimulatory tests in relation to the $24 \mathrm{~h} \mathrm{GH}$ secretion. European Journal of Endocrinology $2006 \mathbf{1 5 4}$ 851-858. (doi:10.1530/eje.1.02163)

21 Ribeiro Oliveira A \& Barkan A. The changing face of acromegalyadvances in diagnosis and treatment. Nature Reviews. Endocrinology 20128 605-611. (doi:10.1038/nrendo.2012.101)

22 Charalampaki P, Ayyad A, Kockro RA \& Perneczky A. Surgical complications after endoscopic transsphenoidal pituitary surgery. Journal of Clinical Neuroscience 200916 786-789. (doi:10.1016/j.jocn. 2008.09.002)

23 Freda PU, Wardlaw SL \& Post KD. Long-term endocrinological followup evaluation in 115 patients who underwent transsphenoidal surgery for acromegaly. Journal of Neurosurgery 199889 353-358. (doi:10.3171/ jns.1998.89.3.0353)

24 Fatemi N, Dusick JR, Mattozo C, McArthur DL, Cohan P, Boscardin J, Wang C, Swerdloff RS \& Kelly DF. Pituitary hormonal loss and recovery after transsphenoidal adenoma removal. Neurosurgery 200863 709-718. (doi:10.1227/01.NEU.0000325725.77132.90)

25 Esposito F, Dusick JR, Cohan P, Moftakhar P, McArthur D, Wang C, Swerdloff RS \& Kelly DF. Clinical review: Early morning cortisol levels as a predictor of remission after transsphenoidal surgery for Cushing's disease. Journal of Clinical Endocrinology and Metabolism 2006 91 7-13. (doi:10.1210/jc.2005-1204)

26 Newell Price J. Transsphenoidal surgery for Cushing's disease: defining cure and following outcome. Clinical Endocrinology 200256 19-21. (doi:10.1046/j.1365-2265.2002.01369.x)

27 Heaney AP \& Melmed S. Molecular targets in pituitary tumours. Nature Reviews. Cancer 20044 285-295. (doi:10.1038/nrc1320)

28 Liu N, Mertani HC, Norstedt G, Törnell J \& Lobie PE. Mode of the autocrine/paracrine mechanism of growth hormone action. Experimental Cell Research 1997237 196-206. (doi:10.1006/excr.1997.3789)

29 Feelders RA, Bidlingmaier M, Strasburger CJ, Janssen JA, Uitterlinden P, Hofland LJ, Lamberts SW, van der Lely AJ \& de Herder WW. Postoperative evaluation of patients with acromegaly: clinical significance and timing of oral glucose tolerance testing and measurement of (free) insulin-like growth factor I, acid-labile subunit, and growth hormone-binding protein levels. Journal of Clinical Endocrinology and Metabolism 200590 6480-6489. (doi:10.1210/ jc.2005-0901)

30 Faria AC, Veldhuis JD, Thorner MO \& Vance ML. Half-time of endogenous growth hormone (GH) disappearance in normal man after stimulation of GH secretion by GH-releasing hormone and suppression with somatostatin. Journal of Clinical Endocrinology and Metabolism 1989 68 535-541. (doi:10.1210/jcem-68-3-535)

31 Lieman HJ, Adel TE, Forst C, von Hagen S \& Santoro N. Effects of aging and estradiol supplementation on GH axis dynamics in women. Journal of Clinical Endocrinology and Metabolism 200186 3918-3923. (doi:10.1210/jcem.86.8.7751)

Received 14 April 2014

Revised version received 16 June 2014

Accepted 18 June 2014 